\title{
Complementopathies and precision medicine
}

\author{
Eleni Gavriilaki ${ }^{1}$ and Robert A. Brodsky² \\ ${ }^{1}$ Hematology Department, G. Papanicolaou Hospital, Thessaloniki, Greece. ²Division of Hematology, Department of Medicine, Johns Hopkins University School of Medicine, Baltimore, Maryland, USA.
}

\begin{abstract}
The renaissance of complement diagnostics and therapeutics has introduced precision medicine into a widened field of complement-mediated diseases. In particular, complement-mediated diseases (or complementopathies) with ongoing or published clinical trials of complement inhibitors include paroxysmal nocturnal hemoglobinuria, cold agglutinin disease, hemolytic uremic syndrome, nephropathies, HELLP syndrome, transplant-associated thrombotic microangiopathy, antiphospholipid antibody syndrome, myasthenia gravis, and neuromyelitis optica. Recognizing that this field is rapidly expanding, we aim to provide a state-of-the-art review of (a) current understanding of complement biology for the clinician, (b) novel insights into complement with potential applicability to clinical practice, (c) complement in disease across various disciplines (hematology, nephrology, obstetrics, transplantation, rheumatology, and neurology), and (d) the potential future of precision medicine. Better understanding of complement diagnostics and therapeutics will not only facilitate physicians treating patients in clinical practice but also provide the basis for future research toward precision medicine in this field.
\end{abstract}

\section{Introduction}

The notion of precision or personalized medicine was introduced in 1999 by Francis Collins based on expected consequences of the Human Genome Project (1). Since then, numerous projects have tried to incorporate genetic and functional disease identities into diagnostic and therapeutic potentials across various disciplines (2). Despite unmet expectations especially in public health issues, precision medicine has expanded, along with a tremendous expansion of complement therapeutics. Indeed, the renaissance of complement therapeutics has led to the recognition of a wide range of complement-mediated disorders, also called "complementopathies" (3). This term has been proposed for disorders in which complement dysregulation drives disease pathogenesis, and complement inhibition has the potential to abate the disease course (4).

Recognizing that this field is rapidly expanding, we aim to provide a state-of-the-art review comprising (a) current understanding of complement biology for the clinician, (b) novel insights into complement with potential applicability to clinical practice, (c) complement in disease across various disciplines (hematology, nephrology, neurology, obstetrics, transplantation, and rheumatology), and (d) our perspective on the future development of precision medicine for complementopathies.

\section{Current understanding of complement biology for the clinician}

More than 50 soluble and membrane-bound proteins form the complement system, providing innate defense against microbes and mediating inflammatory responses $(5,6)$. The complement cascade is activated by the classical, alternative, and lectin pathways. Importantly, the alternative pathway of complement serves as an ampli-

Conflict of interest: RAB is a member of the scientific advisory board for and receives grant funding from Alexion Pharmaceuticals Inc.

Copyright: $\odot 2020$, American Society for Clinical Investigation.

Reference information: J Clin Invest. 2020;130(5):2152-2163.

https://doi.org/10.1172/JCl136094. fication loop for the lectin and classical pathways, accounting for roughly $80 \%$ of complement activation products (7).

The classical pathway is mainly activated by antibodyantigen complexes recognized via complement component C1q. Among antibody isotypes, IgM is the most effective in activating complement. Activation of complement with the four subclasses of IgGs varies as a function of steric hindrance by the Fab arms in the approach of $\mathrm{C} 1 \mathrm{q}$ to the $\operatorname{IgG} \mathrm{CH} 2$ sites (IgG3 $>\operatorname{IgG} 1>\operatorname{IgG} 2>\operatorname{IgG} 4)$ (8). Besides antibodies, C1q also binds directly to certain epitopes from microorganisms or apoptotic cells and to cell surface molecules, such as acute-phase proteins that bind to pathogens or affected cells and activate complement $(9,10)$. C1q subsequently cleaves $\mathrm{C} 1 \mathrm{r}$, which activates $\mathrm{C} 1$ s protease. Then, $\mathrm{C} 1$ s cleaves $\mathrm{C} 4$ and $\mathrm{C} 2$, leading to the formation of classical pathway $\mathrm{C} 3$ convertase (C4bC2a). C3 convertase cleaves $\mathrm{C} 3$, generating the anaphylatoxin $\mathrm{C} 5 \mathrm{a}$ and $\mathrm{C} 5$ convertase $(\mathrm{C} 4 \mathrm{bC} 2 \mathrm{aC} 3 \mathrm{~b})$, which cleaves $\mathrm{C} 5$ into $\mathrm{C} 5 \mathrm{a}$ and $\mathrm{C} 5 \mathrm{~b}$, which initiate the terminal pathway of complement. A schematic of proximal and terminal complement activation is shown in Figure 1.

In the terminal pathway of complement, $\mathrm{C} 5 \mathrm{~b}$ binds to $\mathrm{C} 6$, generating C5b-6, which in turn binds to C7, creating C5b-7. C5b-7 is able to insert into lipid layers of the membrane (11). Once there, C5b-7 binds C8 and C9, forming a complex that unfolds in the membrane and binds several C9 molecules, thereby forming the membrane attack complex (MAC).

\section{Activation of the alternative pathway of complement}

The alternative pathway of complement (APC) is summarized by Figure 2. The APC is continuously activated at low levels through slow spontaneous hydrolysis of $\mathrm{C} 3$, which forms $\mathrm{C} 3\left(\mathrm{H}_{2} \mathrm{O}\right)$. This process is called "tickover." Therefore, the APC can be activated on any surface that has the ability to amplify complement, including the surface of bacteria, apoptotic, and necrotic cells (12). The activated $\mathrm{C} 3\left(\mathrm{H}_{2} \mathrm{O}\right)$ binds factor $\mathrm{B}$, generating $\mathrm{C} 3\left(\mathrm{H}_{2} \mathrm{O}\right) \mathrm{B}$. Factor B is subsequently cleaved by factor $\mathrm{D}$, generating the fluid-phase APC $\mathrm{C} 3$ convertase, or $\mathrm{C} 3\left(\mathrm{H}_{2} \mathrm{O}\right) \mathrm{Bb}$. $\mathrm{C} 3$ convertase then catalyzes the cleavage 


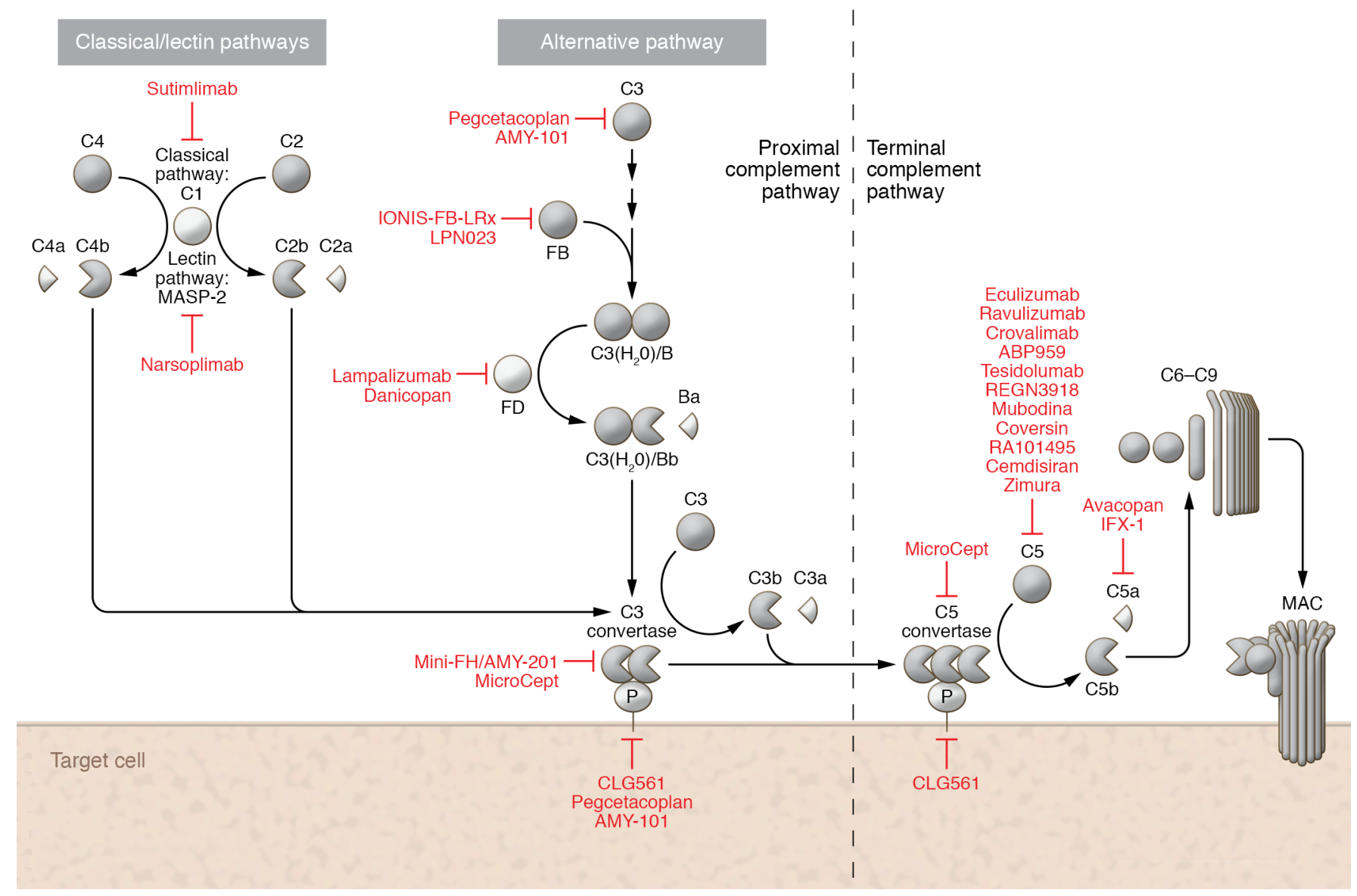

Figure 1. Targets of complement inhibitors in various stages of clinical development for complement-mediated disorders. Complement-targeting compounds are shown in red and indicate the step of the complement pathway they target. From left to right: sutimlimab inhibits C1s of the classical pathway; narsoplimab inhibits mannose-binding protein-associated serine protease 2 (MASP-2) of the lectin pathway; pegcetacoplan (formerly APL-2) and AMY-101 inhibit C3 and C3 convertase activity; IONIS-FB-LRx and LPN023 inhibit factor B; lampalizumab and danicopan inhibit factor D; mini-FH/AMY-201 inhibits alternative pathway C3 convertase; CLC561 inhibits properdin; MicroCept inhibits C3 and C5 convertases; eculizumab, ravulizumab, crovalimab, ABP959, tesidolumab, REGN3918, mubodina, coversin, RA101495, cemdisiran, and zimura inhibit C5; and avacopan inhibits C5a receptor; and IFX-1 inhibits C5a.

of additional $\mathrm{C} 3$ molecules to generate $\mathrm{C} 3 \mathrm{a}$ and $\mathrm{C} 3 \mathrm{~b}$, which attach to cell surfaces (13). This initiates the amplification loop, where C3b pairs with factor $B$ on cell surfaces and bound factor $B$ is cleaved by factor D to generate a second (surface-phase) APC C3 convertase ( $\mathrm{C} 3 \mathrm{bBb})$. Membrane-bound $\mathrm{C} 3$ convertase then cleaves additional $\mathrm{C} 3$ to generate more $\mathrm{C} 3 \mathrm{~b}$ deposits, closing the amplification loop. The binding and cleavage of an additional C3 molecule to C3 convertase forms the APC $\mathrm{C} 5$ convertase (C3bBbC $3 \mathrm{~b}$ ) that cleaves $\mathrm{C} 5$ to $\mathrm{C} 5 \mathrm{a}$ and $\mathrm{C} 5 \mathrm{~b}$. C5b initiates the terminal complement pathway that forms the MAC, as described above. The process, from initial spontaneous $\mathrm{C} 3$ activation through amplification, is depicted in Figure 1. Both C3 and C5 APC convertases are stabilized by properdin (also known as factor P) (14), which also serves as a selective pattern recognition molecule for de novo C3 APC convertase assembly (12). Properdin is the only known positive regulator of complement. It increases the activity of $\mathrm{C} 3$ and $\mathrm{C} 5$ convertases, which amplify $\mathrm{C} 3 \mathrm{~b}$ deposition on cell surfaces (15).

\section{Activation of the lectin pathway of complement}

Lectin pathway activation is initiated by mannose-binding lectins (MBLs) that recognize carbohydrate structures on the surfaces of microbes, such as viruses, protozoan parasites, fungi, and various bacteria $(16,17)$. Other pattern recognition molecules involved in lectin pathway activation are ficolins and collectin 11 (18). These molecules act through MBL-associated serine proteases (MASPs), which generate the $\mathrm{C} 3$ convertase $(\mathrm{C} 4 \mathrm{bC} 2 \mathrm{a})$ in a process similar to that of the classical pathway.

Other mechanisms of complement activation have been postulated, including the interaction with the coagulation cascade (discussed below), and heme-induced complement activation (19). Indeed, a plethora of experimental studies have shown that heme interacts with classical and alternative complement pathways (20). This heme-induced complement activation may be relevant in diseases with intravascular hemolysis. Among them, paroxysmal nocturnal hemoglobinuria (PNH) and complement-mediated hemolytic uremic syndrome (CM-HUS) are well-known models of complement activation and will be further discussed below. In others, such as sickle cell disease, the role of complement activation is currently being investigated (21). Excessive complement activation is physiologically prevented by complement-regulatory proteins. Membrane-bound or soluble complement regulators that are relevant to complement-mediated diseases are summarized in Table 1. 


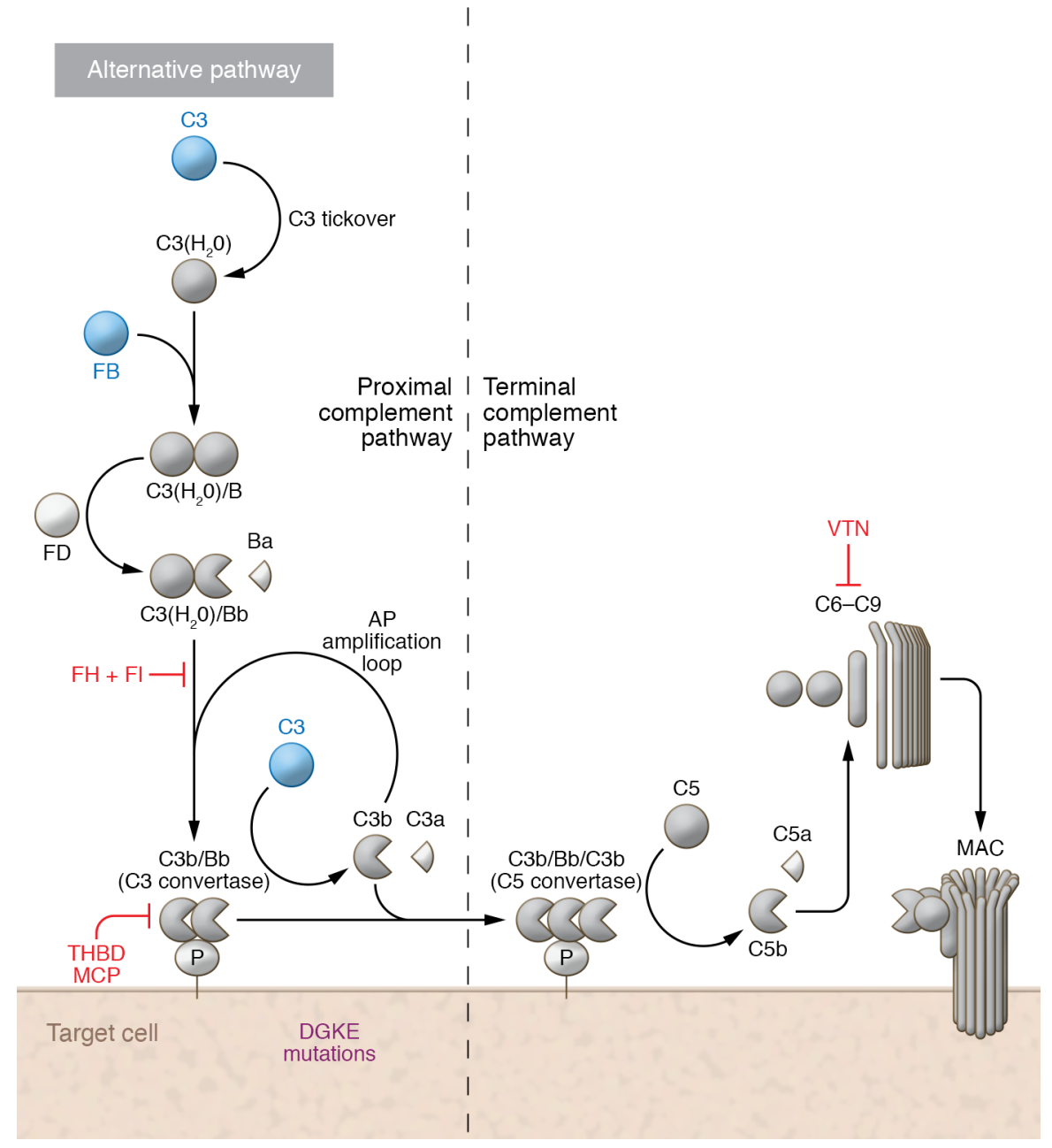

Figure 2. Mutations in complement regulators involved in complement-mediated diseases. Complement activation leads to $\mathrm{C} 3$ activation and C3 convertase formation on C3-opsonized surfaces, culminating in pronounced $\mathrm{C} 3$ fragment deposition on complement-targeted surfaces (proximal complement). In the presence of increased surface density of deposited C3b, the terminal complement is triggered, leading to membrane attack complex (MAC) formation on the surface of target cell. Complement pathway dysregulation results from loss-of-function mutations in regulatory factors (i.e., factor $\mathrm{H}$ $[\mathrm{FH}]$, factor I [FI], thrombomodulin [THBD], and vitronectin [VTN]) shown in red, gain-of-function mutations (i.e., C3 and factor B [FB]) shown in blue, and DGKE mutations in purple, indicating their unknown effect on complement cascade.

\section{Insights into complement potentially applicable to clinical practice}

\section{Immune function of complement}

Complement was first recognized to modulate adaptive immunity in the 1970s (22). Since then, a number of studies have investigated molecular pathways of complement interaction with $\mathrm{B}$ and $\mathrm{T}$ cells (23). Complement modulates innate immune responses by sensing danger signals and interacting with Toll-like receptors (TLRs) (24). Novel pathways have linked complement-mediated signaling with the paracrine and autocrine activation of $\mathrm{T}$ cells, and complement proteins have also been implicated in shaping $\mathrm{T}$ cell fate by acting at the intracellular level, as extensively reviewed by Reis et al. (24). Another emerging feature of complement is the regulation of cell metabolism extending from adipocytes to liver and pancreas (25). Complement also modulates metabolic pathways in immune cells (26), suggesting that inflammation could be restrained by targeting of specific complement proteins. As a result, experimental studies have investigated complement in the immune modulation of diverse inflammatory diseases, including asthma, arthritis, and solid cancer (27-29).

In addition to cells traditionally considered part of the immune system, complement was also recently shown to interact with platelets, which are currently characterized as an innate immune cell (30). Accumulating data suggest that complement and platelets interact during the early cellular and molecular events that promote atherogenesis (31). Interestingly, signaling pathways between platelets and complement act on endothelial cells, affecting their pro-atherogenic features (32). These data suggest the potential involvement of complement in a wide spectrum of diseases associated with atherogenesis.

\section{Complement and thrombosis}

Complement and coagulation were once considered entirely independent pathways; however, it is now clear there is close interaction. Many of the key enzymes in both pathways are serine proteases. Complement-driven diseases, such as $\mathrm{PNH}$, are characterized by a high thrombosis rate that is abrogated by complement inhibition, to the extent that anticoagulation is no longer needed (33).

The underlying mechanisms of complement-mediated thrombosis are not fully clarified, but thrombosis is a prominent clinical feature of all complementopathies. There are multiple proposed mechanisms of complement and thrombosis interactions, as thoroughly reviewed by Hill et al. (34). Direct interactions between complement and coagulation are mediated by C5a (35) and coagulation factors (i.e., thrombin, plasmin, and coagulation factors FXa and FXIa), which can activate complement (36-40). Throm- 
Table 1. Complement regulators relevant to complement-mediated disorders

\begin{tabular}{|c|c|c|c|}
\hline Type & Regulator & Mechanism of regulation & Disorder \\
\hline \multirow[t]{4}{*}{ Membrane bound } & CD55 & Accelerates the decay of cell surface-bound $\mathrm{C} 3$ and $\mathrm{C} 5$ convertases & PNH \\
\hline & CD46 & Accelerates decay of $[3$ convertases; inactivates $[3 \mathrm{~b}$ to iC3b & CM-HUS; glomerulopathies \\
\hline & Complement receptor 1 & Accelerates decay of $\mathrm{C} 3$ and $\mathrm{C} 5$ convertases; cofactor for factor I & CM-HUS; glomerulopathies; CAPS \\
\hline & Vitronectin & Inhibits MAC formation & CM-HUS \\
\hline \multirow[t]{4}{*}{ Soluble } & Factor $\mathrm{H}$ & Disrupts the APC C 3 convertase; cleaves C $3 \mathrm{~b}$ as a cofactor of factor I & CM-HUS; glomerulopathies; HELLP \\
\hline & Factor I & Cleaves cell-bound or fluid-phase C3b and C4b & CM-HUS; glomerulopathies; HELLP \\
\hline & Factor B & Generates the APC C 3 convertase & CM-HUS; glomerulopathies \\
\hline & Factor D & Cleaves factor B & CM-HUS; glomerulopathies \\
\hline
\end{tabular}

APC, alternative pathway of complement; CAPS, catastrophic antiphospholipid antibody syndrome; CM-HUS, complement-mediated hemolytic uremic syndrome; HELLP, hemolysis, elevated liver enzymes, and low platelets (syndrome); MAC, membrane attack complex; PNH, paroxysmal nocturnal hemoglobinuria.

bin was also recently shown to act as a potential C5a convertase in vitro, generating $\mathrm{C}_{\mathrm{T}}$ and $\mathrm{C} 5 \mathrm{~b}_{\mathrm{T}}(41)$.

Indirect effects of complement on thrombosis have also been observed in hemolytic anemias (42). Recent evidence suggests that heme-induced thromboinflammation is significantly attenuated by $\mathrm{C} 5$ inhibition, with additional benefits observed when C5 inhibition is combined with an inhibitor of the TLR coreceptor CD14 (43). In addition, cholesterol crystals can induce coagulation activation via complement-mediated expression of tissue factor (44). This novel notion of thromboinflammation is expected to play a central role in a wide spectrum of disorders, ranging from thrombotic microangiopathies to autoimmune diseases (45).

\section{Complement in disease}

The inability to regulate complement drives the pathophysiology of a variety of diseases that cross multiple medical specialties. These disorders are often associated with specific mutations or autoantibodies that drive complement-mediated end-organ damage. Increasingly, pharmacologic complement inhibition of these pathways mitigates end-organ damage, which lays the foundation for precision medicine in complementopathies. Specific complement inhibitors at different sites of the complement cascade, similar to what exists in coagulation, will soon be widely available. Since these entities are diagnosed and treated by different medical specialties, this section of the Review will focus specifically on disease characteristics and diagnostic and therapeutic features that concern the complement cascade. Table 2 summarizes disorders in which complement inhibition has been shown to be beneficial.

\section{Hematology}

\section{Paroxysmal nocturnal hemoglobinuria}

Complement activation. Paroxysmal nocturnal hemoglobinuria (PNH) is a clonal hematopoietic stem cell disorder caused by somatic mutations in PIGA that lead to the absence of glycosylphosphatidylinositol-anchored (GPI-anchored) proteins on the surfaces of affected cells (33). Two of the missing GPI-anchored proteins (CD55 and CD59) are complement-regulatory proteins $(46,47)$.
Because of their absence from erythrocyte membranes, hemolysis in PNH is primarily due to APC activation. Before 1990, diagnosis of PNH was based on the Ham, or acidified serum, test that was described in the 1930s (48). This test is based on the susceptibility of PNH cells to acidified serum, which serves as an APC activator (48). Thus, incubation of PNH erythrocytes with acidified serum leads to hemolysis that is not observed in normal erythrocytes. Today, $\mathrm{PNH}$ is diagnosed by flow cytometry. Fluoresceinated monoclonal antibodies against GPI-anchored proteins and/or fluoresceinlabeled proaerolysin (FLAER) are used to detect the absence of GPIanchored proteins from the surface of cells in peripheral blood (49, 50 ). Without therapy, the median survival is roughly $15-20$ years; the leading cause of death is thrombosis, highlighting the important link between complement and thrombosis $(51,52)$.

Complement inhibition. Complement inhibition is the treatment of choice for PNH patients with severe hemolytic anemia and/or thrombosis. There are two FDA-approved drugs: eculizumab (approved in 2007) and ravulizumab (approved in 2019). Both monoclonal antibodies bind C5 and sterically hinder cleavage of $\mathrm{C} 5$ by the $\mathrm{C} 5$ convertase. This blocks the generation of the proinflammatory C5a molecule and MAC formation $(53,54)$. Ravulizumab has the advantage of 4-fold longer half-life, but otherwise the drugs are noninferior $(55,56)$. Recently, ravulizumab has shown sustained 1-year safety and efficacy (57), as well as decreased breakthrough hemolysis (58). Both drugs stop intravascular hemolysis, eliminate or reduce the need for blood transfusion, improve quality of life, and markedly attenuate the thrombosis risk. Ravulizumab is currently the drug of choice given its long half-life and more convenient dosing.

Terminal complement inhibition at C5 (downstream of CD55) in PNH usually results in mild to moderate extravascular hemolysis. This is because PNH red cells are also CD55 deficient, leading to unimpaired C3b opsonization and subsequent formation of C3 fragments that result in extravascular hemolysis in the liver and spleen (59). Moreover, complement-amplifying conditions (e.g., pregnancy, surgery, infections) can lead to a high density of surface $\mathrm{C} 3 \mathrm{~b}$ molecules that cause steric hindrance and decrease binding of eculizumab/ravulizumab to C5, ultimately causing breakthrough 
Table 2. Disorders in which complement inhibition is beneficial

Disorder

\section{Mechanism of complement activation}

Age-related macular degeneration

ANCA vasculitis

Antiphospholipid antibody syndrome

Atypical hemolytic uremic syndrome

Cold agglutinin disease

Glomerulopathies

HELLP syndrome

Myasthenia gravis

Neuromyelitis optica

Paroxysmal nocturnal hemoglobinuria

Periodontitis

Transplant-associated TMA
Genetic variants of complement-regulatory proteins

C5a-mediated effects of complement-activating autoantibodies

Cenetic variants of complement-regulatory proteins

Genetic variants of complement-regulatory proteins; autoantibodies

Complement-activating antibodies

Genetic variants of complement-regulatory proteins; autoantibodies

Genetic variants of complement-regulatory proteins

Complement-activating antibodies

Complement-activating antibodies

GPI anchor deficiency

Local microbially induced complement activation

Genetic variants of complement-regulatory proteins
Complement pathway implicated

Alternative

Alternative/classical

Alternative/classical

Alternative

Classical

Alternative/classical

Alternative

Classical

Alternative/classical

Alternative

Alternative

Alternative
Proof of benefit from complement inhibition Phase III clinical trials

Phase III clinical trial

Case reports/series

Approved treatment

Phase III clinical trials

Phase II clinical trials Case reports

Approved treatment

Approved treatment

Approved treatment

Phase II clinical trial

Phase III clinical trial

Disorders are listed alphabetically. ANCA, anti-neutrophil cytoplasmic antibody; GPI, glycosylphosphatidylinositol; HELLP, hemolysis, elevated liver enzymes, and low platelets; TMA, thrombotic microangiopathy.

intravascular hemolysis (60). The only major adverse effect of C5 inhibition has been an expected increased risk of Neisseria meningitidis infection (0.5\% risk annually) (61). The predictable toxicity from C5 inhibition and lack of other major end-organ toxicity are a testament to this precision medicine-based approach.

Novel complement inhibitors are in development, as summarized in Figure 1 (62-64). Among them, crovalimab is a subcutaneously administered monoclonal antibody that also targets $\mathrm{C} 5$ at a different epitope from eculizumab and ravulizumab. It is administered every 4 weeks and, in a phase I/II trial, was able to stop intravascular hemolysis in 10 treatment-naive $\mathrm{PNH}$ patients (65). Inhibition of targets upstream of both CD59 and CD55, such as C3, factor D, and factor $\mathrm{B}$, is even more precise and can block intravascular and extravascular hemolysis because it blocks C3 fragment accumulation on red blood cells (RBCs). In an open-label phase II trial of treatment-naive patients, an oral factor D inhibitor (danicopan) resulted in hemoglobin improvement and elimination of intravascular hemolysis without evidence of C3-mediated extravascular hemolysis (66). In a separate study of 12 eculizumab-treated, transfusion-dependent PNH patients, danicopan was able to improve hemoglobin and eliminate the need for blood transfusions (67). In vitro studies suggest that danicopan preserves classical and lectin pathway activity against invasive pathogens (68). In addition, increased meningococcal killing in vaccinated volunteers has been observed in the presence of danicopan in contrast to anti-C5 inhibitors (69). Pegcetacoplan is a 15-amino acid cyclic peptide conjugated to polyethylene glycol that binds to $\mathrm{C} 3$ and prevents $\mathrm{C} 3$ and $\mathrm{C} 5$ cleavage by their respective convertases. In a phase Ib, open-label clinical study involving 6 transfusion-dependent, eculizumab-treated PNH patients, daily subcutaneous pegcetacoplan was well tolerated, improved hemoglobin, and stopped the need for transfusions (70). Thus, the treatment paradigm for $\mathrm{PNH}$ is likely to change toward a precision medicine model as these novel complement inhibitors enter the clinic.

\section{Cold agglutinin disease}

Complement activation. Cold agglutinins are autoantibodies (typically $\operatorname{IgM}$ ) that agglutinate $\mathrm{RBCs}$ at $4^{\circ} \mathrm{C}$ but may also act at warmer temperatures. Cold agglutinin disease (CAD) is classified as either primary or secondary. Primary CAD is a clonal $\mathrm{B}$ cell lymphoproliferative disorder that is also called primary cold agglutinin-associated lymphoproliferative disease; it is distinct from lymphoplasmacytic lymphoma (MYD88 L265P negative), marginal zone lymphoma, and other low-grade lymphoproliferative diseases (71). Secondary CAD is a syndrome associated with a variety of infectious and neoplastic disorders (aggressive lymphomas, Hodgkin's lymphoma, carcinomas, etc.). Hemolysis is driven by activation of the classical complement pathway, resulting in opsonization and predominantly extravascular hemolysis (72). Cold agglutinins with high thermal amplitude bind to erythrocytes in acral parts of the circulation and often have specificity for the I antigen on RBCs. The IgM cold agglutinin (IgM-CA) antibody activates the classical complement pathway. C1 esterase activates $\mathrm{C} 4$ and $\mathrm{C} 2$, ultimately generating the $\mathrm{C} 3$ convertase, which cleaves $\mathrm{C} 3$ to $\mathrm{C} 3 \mathrm{a}$ and $\mathrm{C} 3 \mathrm{~b}$. Upon return to warmer portions of the circulation $\left(\sim 37^{\circ} \mathrm{C}\right)$, the IgM-CA dissociates from the cell surface, but $\mathrm{C} 3 \mathrm{~b}$ remains bound to the $\mathrm{RBC}$. The $\mathrm{C} 3 \mathrm{~b}$-coated $\mathrm{RBCs}$ are then sequestered by macrophages of the reticuloendothelial system, predominantly in the liver (extravascular hemolysis). C3b of the surviving RBCs is eventually cleaved, leaving a high number of circulating RBCs with C3d on the surface. Patients with CAD have increased early mortality and a high risk of thromboembolism.

Complement inhibition. Rituximab is often used as initial therapy for CAD; it leads to remission (median duration 1 year) in roughly $50 \%$ of patients (73). Sutimlimab is a humanized monoclonal antibody that binds to $\mathrm{C} 1 \mathrm{~s}$ and inhibits classical complement activation (Figure 1). A recent phase Ib trial of sutimlimab in patients with CAD demonstrated that weekly intravenous dosing for 4 weeks followed by biweekly dosing thereafter rapidly aborted complement $\mathrm{C} 1 \mathrm{~s}-$ mediated hemolysis and significantly increased hemoglobin levels, precluding the need for RBC transfusions (74). All patients responded to sutimlimab within a few weeks, with a median rise in hemoglobin of almost $4 \mathrm{~g} / \mathrm{dL}$. Sutimlimab does not affect the production of cold agglutinins or their binding to RBC antigens; thus, CAD patients may still experience acrocyanosis. 
A

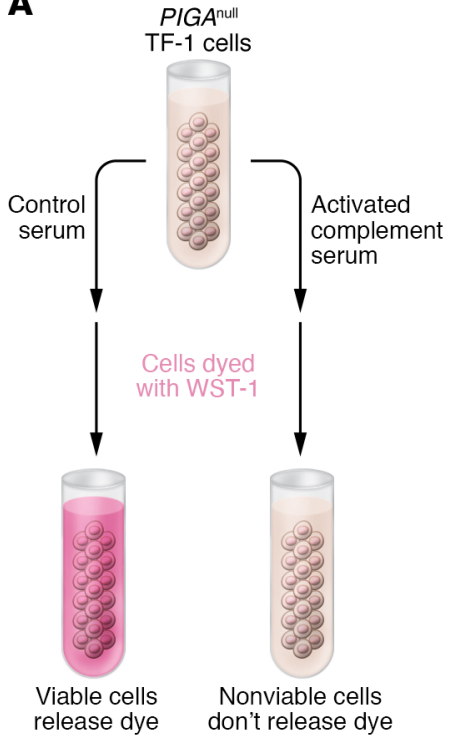

B

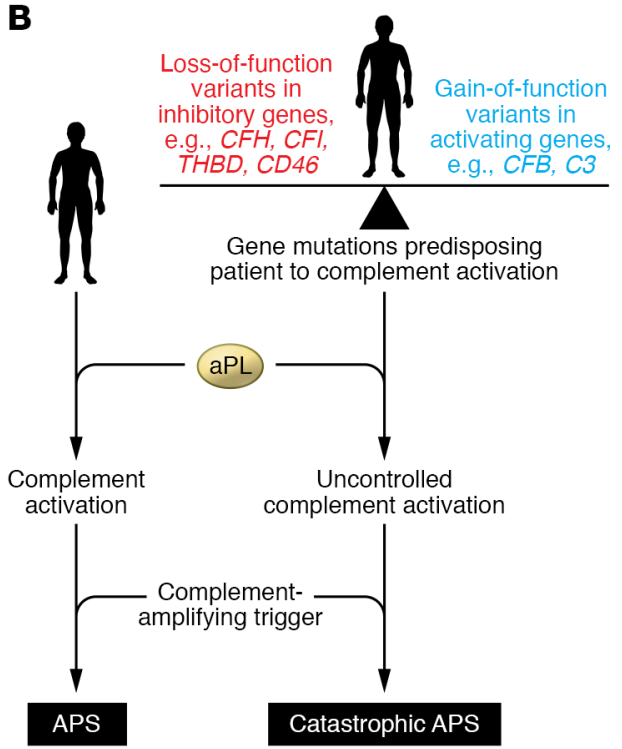

Figure 3. Complementopathies in the clinic. (A) Model of the modified Ham (mHam) test. PIGA ${ }^{\text {nul }}$ (PNH-like) TF1 cells do not express CD55 and CD59 and are therefore susceptible to complementmediated killing. Cells are incubated with patient and control sera, then with a WST-1 cell proliferation dye reagent (Roche). Nonviable cells do not release dye because of complement-mediated killing, resulting in differences in measured absorbance. The percentage of live cells is calculated as the ratio of sample absorbance relative to its heat-inactivated control, multiplied by 100 . The percentage of nonviable cells is a measure of complement activation. (B) Proposed model for APS and CAPS. Recent studies suggest that aPLs induce complement activation in patients with complement-amplifying trigger(s), such as infection, surgery, or autoimmune disease, and cause thrombosis in APS. Patients who also have a pathogenic loss-of-function mutation in a complement-inhibitory factor (e.g., CFH, CFI, CD46, or THBD) or a gain-of-function mutation of a complement-activating factor (e.g., CFB, C3) are likely to be predisposed to uncontrolled complement activation. In the setting of a complement-amplifying trigger, aPL-induced complement activation could lead to disseminated thrombosis and ischemic multiorgan failure in CAPS. PICA, phosphatidylinositol $\mathrm{N}$-acetylglucosaminyltransferase subunit $\mathrm{A} ; \mathrm{PNH}$, paroxysmal nocturnal hemoglobinuria; APS, antiphospholipid syndrome; CAPS, catastrophic antiphospholipid syndrome; aPL, antiphospholipid antibody.

More recently, results from the phase III trial of sutimlimab have demonstrated efficacy in primary endpoints (a composite of hemoglobin increase $\geq 2 \mathrm{~g} / \mathrm{dL}$ or hemoglobin $\geq 12 \mathrm{~g} / \mathrm{dL}$ at treatment assessment [average from weeks 23,25 , and 26] and transfusion avoidance from week 5 to week 26) and secondary endpoints (change from baseline in hemolytic markers and quality of life) (75). Thus, targeting of C1s with sutimlimab, a more precise target than CD20, will likely become standard therapy for CAD.

\section{Nephrology}

\section{Atypical or complement-mediated hemolytic uremic syndrome}

Complement activation. Atypical hemolytic uremic syndrome (aHUS) presents as a thrombotic microangiopathy (TMA) with the clinical triad of microangiopathic hemolytic anemia, thrombocytopenia, and organ damage (76) with preserved function of the disintegrin and metalloproteinase ADAMTS13. Among TMAs, aHUS has long served as an archetypal disease model of complement dysregulation. Recently, two published consensus documents have changed the terminology of TMAs from a model based on underlying disease to a pathophysiology-driven model $(77,78)$, introducing the term complement-mediated HUS

(CM-HUS). The prevalent "two-hit" hypothesis for CM-HUS pathogenesis is that genetic or acquired (e.g., anti-complement factor $\mathrm{H}$ autoantibodies) defects in complement regulation shape a predisposing phenotype toward excessive complement activation. This complement phenotype is then coupled to a second hit that propagates complement amplification $(79,80)$. Complement-amplifying conditions are often infections, autoimmunity, surgery, pregnancy, or cancer.

CM-HUS-associated mutations cause either loss of function of complement-regulatory proteins, including complement factor $\mathrm{H}(\mathrm{CFH})$, complement factor I (CFI), thrombomodulin (THBD), and CD46/membrane cofactor protein (MCP), or gain of function of complement-activating proteins, including complement factor B (CFB) and C3 (81). Although THBD may also act as a complement regulator (82), further studies are needed to confirm the roles of coagulation pathway proteins (83). A recent study also revealed mutations in VTN, which encodes the terminal complement inhibitor vitronectin, in CM-HUS patients (84). The only mutations in this disease that are not associated with complement dysregulation are found in diacylglycerol kinase- $\varepsilon$ (DGKE) $(85,86)$. Figure 2 summarizes mutations in these complement-related proteins. These germline variants in genes that regulate the APC are present in about $50 \%$ of patients with CM-HUS $(87,88)$. Factor $\mathrm{H}$ autoantibodies may also be found in up to $10 \%$ of CM-HUS (89). The majority of these patients lack CFHR1 and CFHR3, owing to homozygous deletion of the genomic region that expresses them (90). Sequencing results do not affect early treatment decisions given the acute presentation, the time it takes to get results, and the uncertainty regarding the relevance of some germline variants (91).

Traditional biomarkers used in clinical complement laboratories, such as hemolytic assays of classical and alternative pathway activity (CH-50 and AP-50, respectively) and ELISA of $\mathrm{C} 3$ concentration or APC activity (Wieslab), are not reliable for CM-HUS diagnosis (92). Soluble C5b-9 is not diagnostic for CM-HUS because values have a substantial overlap with other TMAs (93). Translational studies have also used C5b-9 deposition on endothelial cells to detect evidence of complement activation in patients with TMAs $(94,95)$. In vivo deposition of C5b-9 on dermal microvessels in the transplant setting has also been shown (96). In an effort to develop a rapid and reliable in vitro diagnostic assay for CM-HUS, the modified Ham test has been suggested, as described in Figure 3A (97). The latter can distinguish between CM-HUS and thrombotic thrombocytopenic purpura (TTP), but the assay is not yet available in clinical laboratories (97-99).

Complement inhibition. CM-HUS is an urgent life-threatening syndrome requiring prompt initiation of therapy (100). The 
diagnosis is suspected in a patient with TMA who is Shiga toxinnegative with ADAMTS13 activity over 10\%. Distinction between TTP and CM-HUS is important, as plasma exchange does not reliably arrest the complement-mediated organ damage occurring in CM-HUS (101). Improvements in platelet count and lactate dehydrogenase (LDH) are usually seen within days of eculizumab administration $(102,103)$. Kidney recovery may take several weeks to months (104). Eculizumab is administered intravenously every 7 days for the first 5 weeks and biweekly thereafter; however, the optimal duration of therapy is unclear $(103,105,106)$. While early reports suggested that long-term/indefinite therapy is required, more recent reports suggest that eculizumab may be safely discontinued in many CM-HUS patients (107-109). Before eculizumab is discontinued, the patient should be in complete remission (normal platelet counts, $\mathrm{LDH}$, and renal function) and potential complement-activating "triggers" should be controlled. In addition to the risk of meningitis mentioned in association with $\mathrm{PNH}$, eculizumab hepatotoxicity has been reported in pediatric CM-HUS (110).

\section{Glomerulopathies}

Glomerulopathies consist of a wide range of diseases in the majority of which complement plays a central role. C3 glomerulopathy (C3G) is characterized by APC activation leading to C3 deposition in the glomeruli (111). Recent studies have found complementrelated mutations in $\mathrm{C} 3 \mathrm{G}$, similar to those of $\mathrm{CM}-\mathrm{HUS}$. Interestingly, mutations in $\mathrm{C} 3 \mathrm{G}$ cause different protein changes and, therefore, different phenotypes compared with CM-HUS mutations (112). These discoveries, along with experimental models of complement dysregulation (113), have prompted studies of complement inhibitors in these patients. Indeed, eculizumab has been administered in case reports and series of C3G transplant recipients (114-116). However, since the principal defect is caused by proximal complement activation, specific blockade is expected to show higher efficacy. Ongoing clinical trials are examining the efficacy of specific blockade in C3G with narsoplimab, sutimlimab, danicopan, and avacopan (Figure 1), all of which block complement activation more proximally. Apart from C3G, IgA nephropathy, lupus nephritis, and membranous nephropathy are also under study with complement inhibitors (117).

\section{Obstetrics: HELLP syndrome}

HELLP (hemolysis, elevated liver enzymes, and low platelets) syndrome usually arises in the third trimester of pregnancy and resolves shortly after delivery (118). Although its pathogenesis is not fully clear, endothelial dysfunction, partly mediated by complement, plays a central role. Fetal mortality approaches 30\% when HELLP syndrome occurs early in the third trimester; maternal mortality may also approach $5 \%$ to $10 \%$. Investigators have hypothesized that CM-HUS and HELLP syndrome may share a similar pathophysiology, because the clinical manifestations of hypertension, renal insufficiency, thrombocytopenia, elevated $\mathrm{LDH}$, elevated aspartate aminotransterase, and even the presence of schistocytes are common to both disorders. Recent data using next-generation sequencing and functional complement assays in HELLP patients support this hypothesis $(98,99)$. Similar to $\mathrm{CM}-\mathrm{HUS}$, rare germline variants (variant allele frequency $<1 \%$ ) in genes regulating the $\mathrm{APC}$ (e.g., $\mathrm{C} 3, \mathrm{CFH}, \mathrm{CFB}, \mathrm{MCP}$, etc.) and/or activation of complement using the modified Ham test are found in up to $50 \%$ of patients with HELLP syndrome (98, 99). These data suggest that, as with CM-HUS, a large subset of HELLP syndrome is driven by an inability to regulate complement. The thrombocytopenia is consumptive, the hemolysis is mechanical, and the elevated "liver function tests" (LDH, bilirubin, and aspartate aminotransferase) are actually markers of intravascular hemolysis rather than intrinsic liver dysfunction. Germline mutations in genes that regulate the APC may predispose to HELLP syndrome. Complement levels normally rise after the second trimester of pregnancy and may serve as a complement amplifier, along with other factors (autoimmunity, infection, etc.) that contribute to vascular damage $(119,120)$. Complement levels decrease following delivery, possibly explaining why the disease typically resolves postpartum. There are now several case reports describing the use of eculizumab to treat HELLP syndrome, but this is not an FDA-approved use of the drug (121).

\section{Transplantation: transplant-associated thrombotic microangiopathy}

Transplant-associated TMA (TA-TMA) is a potentially life-threatening complication of allogeneic hematopoietic cell transplantation (HCT) (122). Although it manifests with the clinical triad of a TMA, diagnosis is largely hindered by the high incidence of cytopenias and organ dysfunction in HCT recipients. Current diagnostic criteria have been criticized for their diagnostic sensitivity (123). Moving the field forward, a growing number of genetic and functional data suggest increased complement activation in both the adult and pediatric population of TA-TMA (124-126). Soluble C5b-9 levels were also incorporated into recently proposed severity criteria of TA-TMA aiming to facilitate early diagnosis and treatment (127).

Eculizumab treatment is increasingly used to treat both adult and pediatric patients with TA-TMA (128-132). Despite high response rates to eculizumab treatment that reach $93 \%$, overall survival remains low $(\sim 30 \%)$ in early reports from the adult population $(130,131)$. However, a recent study of 64 pediatric TA-TMA patients has shown an increased 1-year survival of $66 \%$ in eculizumab-treated patients compared with $17 \%$ in a historic control group (132). Several issues remain to be further investigated: timing of initiation, proper patient selection, dosing, and duration of therapy in patients with transplants. Interestingly, a novel C5 inhibitor, coversin, was successfully used in a TA-TMA patient with a C5 variant that caused resistance to eculizumab treatment (133). Recently, a phase II single-arm, open-label study of an inhibitor of the lectin pathway, the MASP-2 inhibitor OMS721/narsoplimab, in 19 TA-TMA patients also reported increased median overall survival in comparison with a historical control of conventional treatment (347 vs. 21 days from TA-TMA diagnosis) (134). As a result, a phase III clinical trial is ongoing (Table 2).

\section{Rheumatology: antiphospholipid antibody syndrome}

Antiphospholipid antibody syndrome (APS) is an acquired thrombophilia characterized by thrombosis affecting the venous or arterial vascular systems and/or obstetrical morbidity with the persistent presence of antiphospholipid antibodies, including lupus anticoagulant, anticardiolipin antibody, and anti- $\beta_{2}$-glycopro- 
tein-I (anti-32GPI) (135). A severe form of APS characterized by widespread thrombosis and multi-organ failure developing over less than a week, termed catastrophic APS (CAPS), affects a subset $(\sim 1 \%)$ of APS patients. CAPS often presents as a TMA and has a fulminant course with more than $40 \%$ mortality despite the best available therapy $(136,137)$.

Complement activation has been shown in murine models of APS, suggesting a crucial role of complement in antiphospholipid antibody-mediated thrombosis (138-141) and obstetric (142-144) complications. Increased C5b-9 (145), Bb fragments, and C3a (146, 147) have been observed in APS sera (148). More recent data demonstrate that complement activation in APS is triggered by anti- $\beta 2 \mathrm{G}-$ PI antibodies (149). A positive modified Ham test, as described in Figure 3A, was highly predictive for thrombotic events. Moreover, more than $50 \%$ of patients with CAPS harbor rare germline variants in complement-regulatory genes, similarly to CM-HUS and HELLP syndrome patients. This may explain the more severe CAPS phenotype, as demonstrated in Figure 3B (149). In line with these data, several reports have documented efficacy of eculizumab in refractory thrombotic APS (150) and CAPS (151-154). Finally, eculizumab prevented recurrence of APS and enabled renal transplantation in three APS patients (155). Thus, future studies of complement inhibition are indicated for severe forms of APS and CAPS.

\section{Neurology}

\section{Myasthenia gravis}

The majority of myasthenia gravis (MG) patients express acetylcholine receptor antibodies (AChR-Abs) (156). These antibodies bind C1q, activate the complement cascade, and ultimately lead to MAC generation. Initial evidence of complement activation in MG patients (157-160) has been confirmed in complement-deficient mouse models, suggesting a crucial role of MAC-mediating signals in MG (161-165). Complement was successfully targeted with passive and active experimental studies in MG (166). These data led to the phase III randomized double-blind placebo-controlled REGAIN trial in 125 patients with AChR-Ab-positive refractory generalized MG (167). Based on significant improvements in activities of daily living, muscle strength, and health-related quality of life, eculizumab received regulatory approval for treatment of these patients.

\section{Neuromyelitis optica spectrum disorder}

Neuromyelitis optica spectrum disorder (NMOSD) is a rare disorder of the central nervous system traditionally considered an autoimmune inflammatory disease and treated mainly with immunosuppressive agents such as rituximab (168). Antibodies against aquaporin-4 (AQP4) are found in the majority of patients
$(169,170)$ and have been shown to activate complement in vitro and in vivo $(171,172)$. Complement-mediated death of neurons near astrocytes was mitigated by complement inhibition (173). In this context, upregulation of the complement regulator CD55 has reduced NMOSD pathology (174).

A phase II study of eculizumab in 14 patients has shown the potential of the drug to prevent relapses (175). These results have been confirmed in the most recent randomized, double-blind, time-to-event trial in 143 AQP4-positive patients (176). It should be noted, however, that eculizumab did not improve measures of disability progression, suggesting that long-term administration needs to be evaluated in light of two additional clinical trials of immunotherapeutic agents in patients with NMOSD (177).

\section{Conclusion and future perspectives}

Over the past few decades, our understanding of complement and precision medicine has evolved. Terminal complement inhibition is currently the mainstay of treatment for complement-mediated disorders, or complementopathies, across multiple medical specialties. Potentially novel indications span various disciplines, including hematology, nephrology, obstetrics, transplantation, rheumatology, and neurology. Complement involvement has been speculated in a wide range of entities that have not been described in detail in this Review, such as age-related macular degeneration (178), hyperhemolysis syndrome (21), neurodegenerative diseases (62), periodontitis (179), and anti-neutrophil cytoplasmic antibody (ANCA) vasculitis (180). Improvements in genetic and functional assays coupled with numerous novel and highly specific complement inhibitors will only increase the personalized approach to treating complementopathies.

\section{Acknowledgments}

Given the broad scope of this Review, the authors often refer to specialized review articles rather than primary literature, and they have been able to include only selected examples of original work in the field. Therefore, the authors thank colleagues who are not specifically cited for their contribution and their understanding. EG is co-financed by Greece and the European Union (European Social Fund- ESF) through the Operational Programme (Human Resources Development, Education and Lifelong Learning 2014-2020) (MIS 5033021), enabled through the State Scholarships Foundation. RB received funding support from NIH/NHLBI R01HL133113.

Address correspondence to: Robert A. Brodsky, Johns Hopkins University School of Medicine, 720 Rutland Avenue, Ross 1025, Baltimore, Maryland 21205, USA. Phone: 410.502.2546; Email: brodsro@jhmi.edu.
1. Collins FS. The human genome project and the future of medicine. Ann N Y Acad Sci. 1999;882:42-55.

2. Joyner MJ, Paneth N. Promises, promises, and precision medicine. JClin Invest. 2019;129(3):946-948.

3. Merrill SA, Brodsky RA. Complement-driven anemia: more than just paroxysmal nocturnal hemoglobinuria. Hematology Am Soc Hematol Educ Program. 2018;2018(1):371-376.

4. Baines AC, Brodsky RA. Complementopathies. Blood Rev. 2017;31(4):213-223.

5. Varela JC, Tomlinson S. Complement: an overview for the clinician. Hematol Oncol Clin North Am. 2015;29(3):409-427.

6. Walport MJ. Complement. First of two parts.
N Engl J Med. 2001;344(14):1058-1066.

7. Harboe M, Mollnes TE. The alternative complement pathway revisited. J Cell Mol Med. 2008;12(4):1074-1084.

8. Brunhouse R, Cebra JJ. Isotypes of IgG: comparison of the primary structures of three pairs of isotypes which differ in their ability to activate complement. Mol Immunol. 1979;16(11):907-917. 
9. Gewurz AT, Lint TF, Imherr SM, Garber SS, Gewurz H. Detection and analysis of inborn and acquired complement abnormalities. Clin Immunol Immunopathol. 1982;23(2):297-311.

10. Mold C, Gewurz H, Du Clos TW. Regulation of complement activation by C-reactive protein Immunopharmacology. 1999;42(1-3):23-30.

11. Preissner KT, Podack ER, Müller-Eberhard HJ. The membrane attack complex of complement: relation of $\mathrm{C} 7$ to the metastable membrane binding site of the intermediate complex C5b-7. J Immunol. 1985;135(1):445-451.

12. Cortes C, Ohtola JA, Saggu G, Ferreira VP. Local release of properdin in the cellular microenvironment: role in pattern recognition and amplification of the alternative pathway of complement. Front Immunol. 2012;3:412.

13. Pangburn MK, Müller-Eberhard HJ. Initiation of the alternative complement pathway due to spontaneous hydrolysis of the thioester of C3. Ann N Y Acad Sci. 1983;421:291-298.

14. Chapitis J, Lepow IH. Multiple sedimenting species of properdin in human serum and interaction of purified properdin with the third component of complement. JExp Med. 1976;143(2):241-257.

15. Ferreira VP. Properdin. In: Barnum S, Schein T, eds. The Complement FactsBook. 2nd ed. London, United Kingdom: Elsevier; 2018:283-293.

16. Neth O, Jack DL, Dodds AW, Holzel H, Klein NJ, Turner MW. Mannose-binding lectin binds to a range of clinically relevant microorganisms and promotes complement deposition. Infect Immun. 2000;68(2):688-693

17. Saifuddin M, Hart ML, Gewurz H, Zhang Y, Spear GT. Interaction of mannose-binding lectin with primary isolates of human immunodeficiency virus type 1. J Gen Virol. 2000;81(pt 4):949-955.

18. Héja D, et al. Revised mechanism of complement lectin-pathway activation revealing the role of serine protease MASP-1 as the exclusive activator of MASP-2. Proc Natl Acad Sci U S A. 2012;109(26):10498-10503.

19. Gavriilaki E, Brodsky RA. Complement-mediated coagulation disorders: paroxysmal nocturnal hemoglobinuria and atypical hemolytic uremic syndrome. In: Kitchens C, Kessler C, Konkle BA, Streiff MB, Garcia DA, eds. Consultative Hemostasis and Thrombosis. 4th ed. Philadelphia, Pennsylvania, USA: Elsevier; 2019:473-490.

20. Merle NS, Boudhabhay I, Leon J, FrémeauxBacchi V, Roumenina LT. Complement activation during intravascular hemolysis: Implication for sickle cell disease and hemolytic transfusion reactions. Transfus Clin Biol. 2019;26(2):116-124.

21. Merrill SA, Brodsky RA, Lanzkron SM, Naik R. A case-control analysis of hyperhemolysis syndrome in adults and laboratory correlates of complement involvement. Transfusion 2019;59(10):3129-3139.

22. Eden A, Miller GW, Nussenzweig V. Human lymphocytes bear membrane receptors for C3b and C3d. J Clin Invest. 1973;52(12):3239-3242.

23. Dempsey PW, Allison ME, Akkaraju S, Goodnow CC, Fearon DT. C3d of complement as a molecular adjuvant: bridging innate and acquired immunity. Science. 1996;271(5247):348-350.

24. Reis ES, Mastellos DC, Hajishengallis G, Lambris JD. New insights into the immune functions of complement. Nat Rev Immunol. 2019;19(8):503-516.

25. Phieler J, Garcia-Martin R, Lambris JD, Chavakis $\mathrm{T}$. The role of the complement system in metabolic organs and metabolic diseases. Semin Immunol. 2013;25(1):47-53.

26. Geltink RIK, Kyle RL, Pearce EL. Unraveling the complex interplay between $\mathrm{T}$ cell metabolism and function. Annu Rev Immunol. 2018;36:461-488.

27. Lajoie $S$, et al. Complement-mediated regulation of the IL-17A axis is a central genetic determinant of the severity of experimental allergic asthma. Nat Immunol. 2010;11(10):928-935.

28. Hashimoto M, et al. Complement drives Th17 cell differentiation and triggers autoimmune arthritis. JExp Med. 2010;207(6):1135-1143.

29. Ricklin D, Hajishengallis G, Yang K, Lambris JD. Complement: a key system for immune surveillance and homeostasis. Nat Immunol. 2010;11(9):785-797.

30. Eriksson O, Mohlin C, Nilsson B, Ekdahl KN. The human platelet as an innate immune cell: interactions between activated platelets and the complement system. Front Immunol. 2019;10:1590.

31. Patzelt J, Verschoor A, Langer HF. Platelets and the complement cascade in atherosclerosis. Front Physiol. 2015;6:49.

32. Speth C, et al. Complement and platelets: mutua interference in the immune network. Mol Immunol. 2015;67(1):108-118.

33. Brodsky RA. Paroxysmal nocturnal hemoglobinuria. Blood. 2014;124(18):2804-2811.

34. Hill A, Kelly RJ, Hillmen P. Thrombosis in paroxysmal nocturnal hemoglobinuria. Blood. 2013;121(25):4985-4996.

35. Ritis K, et al. A novel C5a receptor-tissue factor cross-talk in neutrophils links innate immunity to coagulation pathways. JImmunol. 2006;177(7):4794-4802.

36. Rittirsch D, Flierl MA, Ward PA. Harmful molecular mechanisms in sepsis. Nat Rev Immunol. 2008;8(10):776-787.

37. Clark A, et al. Evidence for non-traditional activation of complement factor C3 during murine liver regeneration. Mol Immunol. 2008;45(11):3125-3132.

38. Amara U, et al. Molecular intercommunication between the complement and coagulation systems. J Immunol. 2010;185(9):5628-5636.

39. Leung LL, Morser J. Plasmin as a complement C5 convertase. EBioMedicine. 2016;5:20-21.

40. Huber-Lang M, et al. Generation of C5a in the absence of C3: a new complement activation pathway. Nat Med.2006;12(6):682-687.

41. Krisinger MJ, et al. Thrombin generates previously unidentified C5 products that support the terminal complement activation pathway. Blood. 2012;120(8):1717-1725.

42. Chapin J, Terry HS, Kleinert D, Laurence J. The role of complement activation in thrombosis and hemolytic anemias. Transfus Apher Sci. 2016;54(2):191-198.

43. Thomas AM, et al. Complement component C5 and TLR molecule CD14 mediate heme-induced thromboinflammation in human blood. JImmunol. 2019;203(6):1571-1578.

44. Gravastrand CS, et al. Cholesterol crystals induce coagulation activation through complement- dependent expression of monocytic tissue factor. JImmunol. 2019;203(4):853-863.

45. Jackson SP, Darbousset R, Schoenwaelder SM. Thromboinflammation: challenges of therapeutically targeting coagulation and other host defense mechanisms. Blood. 2019;133(9):906-918.

46. Lublin DM, Atkinson JP. Decay-accelerating factor: biochemistry, molecular biology, and function. Annu Rev Immunol. 1989;7:35-58.

47. Rollins SA, Sims PJ. The complement-inhibitory activity of CD59 resides in its capacity to block incorporation of C9 into membrane C5b-9. Jimmunol. 1990;144(9):3478-3483.

48. Ham TH, Dingle JH. Studies on destruction of red blood cells. II. Chronic hemolytic anemia with paroxysmal nocturnal hemoglobinuria: certain immunological aspects of the hemolytic mechanism with special reference to serum complement. J Clin Invest. 1939;18(6):657-672.

49. Brodsky RA, et al. Improved detection and characterization of paroxysmal nocturnal hemoglobinuria using fluorescent aerolysin. Am J Clin Pathol. 2000;114(3):459-466.

50. Borowitz MJ, et al. Guidelines for the diagnosis and monitoring of paroxysmal nocturnal hemoglobinuria and related disorders by flow cytometry. Cytometry B Clin Cytom. 2010;78(4):211-230.

51. Moyo VM, Mukhina GL, Garrett ES, Brodsky RA. Natural history of paroxysmal nocturnal haemoglobinuria using modern diagnostic assays. $\mathrm{Br} \mathrm{J}$ Haematol. 2004;126(1):133-138.

52. Hillmen P, Lewis SM, Bessler M, Luzzatto L, Dacie JV. Natural history of paroxysmal nocturnal hemoglobinuria. $N$ Engl J Med. 1995;333(19):1253-1258.

53. Hillmen P, et al. The complement inhibitor eculizumab in paroxysmal nocturnal hemoglobinuria. N Engl J Med. 2006;355(12):1233-1243.

54 . Brodsky RA, et al. Multicenter phase 3 study of the complement inhibitor eculizumab for the treatment of patients with paroxysmal nocturnal hemoglobinuria. Blood. 2008;111(4):1840-1847.

55. Kulasekararaj AG, et al. Ravulizumab (ALXN1210) vs eculizumab in C5-inhibitorexperienced adult patients with PNH: the 302 study. Blood. 2019;133(6):540-549.

56. Lee JW, et al. Ravulizumab (ALXN1210) vs eculizumab in adult patients with $\mathrm{PNH}$ naive to complement inhibitors: the 301 study. Blood. 2019;133(6):530-539.

57. Kulasekararaj AH, et al. One-year efficacy and safety from a phase 3 trial of ravulizumab in adult patients with paroxysmal nocturnal hemoglobinuria receiving prior eculizumab treatment. Blood. 2019;134(suppl 1):2231.

58. Brodsky RA, et al. Characterization of breakthrough hemolysis events observed in the phase 3 randomized studies of ravulizumab versus eculizumab in adults with paroxysmal nocturnal hemoglobinuria [published online ahead of print January 16, 2020]. Haematologica. https://doi org/10.3324/haematol.2019.236877.

59. Risitano AM, et al. Complement fraction 3 binding on erythrocytes as additional mechanism of disease in paroxysmal nocturnal hemoglobinuria patients treated by eculizumab. Blood. 2009;113(17):4094-4100.

60. Harder MJ, et al. Incomplete inhibition by ecu- 
lizumab: mechanistic evidence for residual C5 activity during strong complement activation. Blood. 2017;129(8):970-980.

61. Winthrop KL, et al. ESCMID Study Group for Infections in Compromised Hosts (ESGICH) Consensus Document on the safety of targeted and biological therapies: an infectious diseases perspective (Soluble immune effector molecules [II]: agents targeting interleukins, immunoglobulins and complement factors). Clin Microbiol Infect. 2018;24(suppl 2):S21-S40.

62. Morgan BP, Harris CL. Complement, a target for therapy in inflammatory and degenerative diseases. Nat Rev Drug Discov. 2015;14(12):857-877.

63. Ricklin D, Mastellos DC, Reis ES, Lambris JD. The renaissance of complement therapeutics. Nat Rev Nephrol. 2018;14(1):26-47.

64. Mastellos DC, Reis ES, Yancopoulou D, Risitano AM, Lambris JD. Expanding complement therapeutics for the treatment of paroxysmal nocturnal hemoglobinuria. Semin Hematol. 2018;55(3):167-175.

65. Röth A, et al. The complement C5 inhibitor crovalimab in paroxysmal nocturnal hemoglobinuria. Blood.2020;135(12):912-920.

66. Risitano AL, et al. Mechanistic evaluation of efficacy using biomarkers of the oral, small molecule factor dinhibitor, danicopan (ACH-4471), in untreated patients with paroxysmal nocturnal hemoglobinuria (PNH). Blood. 2019;134(suppl 1):2226.

67. Kulasekararaj AR, et al. A phase 2 open-label study of danicopan (ACH-0144471) in patients with paroxysmal nocturnal hemoglobinuria (PNH) who have an inadequate response to eculizumab monotherapy. Blood. 2019;134(suppl 1):3514.

68. Kumar CG, Sujitha P. Kocuran, an exopolysaccharide isolated from Kocuria rosea strain BS- 1 and evaluation of its in vitro immunosuppression activities. Enzyme Microb Technol. 2014;55:113-120.

69. Konar M, Granoff DM. Eculizumab treatment and impaired opsonophagocytic killing of meningococci by whole blood from immunized adults. Blood. 2017;130(7):891-899.

70. Wong RSM. Inhibition of C 3 with APL-2 results in normalisation of markers of intravascular and extravascular hemolysis in patients with paroxysmal nocturnal hemoglobinuria (PNH). Blood. 2018;132(suppl 1):2314.

71. Randen U, et al. Primary cold agglutininassociated lymphoproliferative disease: a B-cell lymphoma of the bone marrow distinct from lymphoplasmacytic lymphoma. Haematologica. 2014;99(3):497-504.

72. Sokol RJ, Hewitt S, Stamps BK. Autoimmune haemolysis: an 18-year study of 865 cases referred to a regional transfusion centre. $\mathrm{Br}$ Med J (Clin Res Ed). 1981;282(6281):2023-2027.

73. Berentsen S, et al. Rituximab for primary chronic cold agglutinin disease: a prospective study of 37 courses of therapy in 27 patients. Blood. 2004;103(8):2925-2928.

74. Jäger $\mathrm{U}$, et al. Inhibition of complement $\mathrm{C} 1 \mathrm{~s}$ improves severe hemolytic anemia in cold agglutinin disease: a first-in-human trial. Blood. 2019;133(9):893-901.

75. Röth A, et al. Inhibition of complement C1s with sutimlimab in patients with cold agglutinin disease (CAD): results from the phase 3 Cardinal
Study. Blood. 2019;134(suppl 2):LBA-2.

76. Gavriilaki E, Anagnostopoulos A, Mastellos DC. Complement in thrombotic microangiopathies: unraveling Ariadne's thread into the labyrinth of complement therapeutics. Front Immunol. 2019;10:337.

77. Loirat C, et al. An international consensus approach to the management of atypical hemolytic uremic syndrome in children. Pediatr Nephrol. 2016;31(1):15-39.

78. Scully M. Consensus on the standardization of terminology in thrombotic thrombocytopenic purpura and related thrombotic microangiopathies. J Thromb Haemost. 2017;15(2):312-322.

79. May O, et al. Heme drives susceptibility of glomerular endothelium to complement overactivation due to inefficient upregulation of heme oxygenase-1. Front Immunol. 2018;9:3008.

80. Nester CM, et al. Atypical aHUS: state of the art. Mol Immunol. 2015;67(1):31-42.

81. Rodríguez de Córdoba S, Hidalgo MS, Pinto S, Tortajada A. Genetics of atypical hemolytic uremic syndrome (aHUS). Semin Thromb Hemost. 2014;40(4):422-430.

82. Delvaeye $\mathrm{M}$, et al. Thrombomodulin mutations in atypical hemolytic-uremic syndrome. $\mathrm{N}$ Engl J Med. 2009;361(4):345-357.

83. Fakhouri F, Zuber J, Frémeaux-Bacchi V, Loirat C. Haemolytic uraemic syndrome. Lancet. 2017;390(10095):681-696.

84. Bu F, et al. Genetic analysis of 400 patients refines understanding and implicates a new gene in atypical hemolytic uremic syndrome. J Am Soc Nephrol. 2018;29(12):2809-2819.

85. Lemaire M, et al. Recessive mutations in DGKE cause atypical hemolytic-uremic syndrome. Nat Genet. 2013;45(5):531-536.

86. Bruneau S, et al. Loss of DGK $\varepsilon$ induces endothelial cell activation and death independently of complement activation. Blood. 2015;125(6):1038-1046

87. Bresin E, et al. Combined complement gene mutations in atypical hemolytic uremic syndrome influence clinical phenotype. J Am Soc Nephrol. 2013;24(3):475-486.

88. Noris M, et al. Relative role of genetic complement abnormalities in sporadic and familial aHUS and their impact on clinical phenotype. Clin J Am Soc Nephrol. 2010;5(10):1844-1859.

89. Brocklebank V, et al. Factor $\mathrm{H}$ autoantibody is associated with atypical hemolytic uremic syndrome in children in the United Kingdom and Ireland. Kidney Int. 2017;92(5):1261-1271.

90. Bhattacharjee A, et al. The major autoantibody epitope on factor $\mathrm{H}$ in atypical hemolytic uremic syndrome is structurally different from its homologous site in factor $\mathrm{H}$-related protein 1 , supporting a novel model for induction of autoimmunity in this disease. J Biol Chem. 2015;290(15):9500-9510.

91. Brodsky RA. Complement in hemolytic anemia. Blood. 2015;126(22):2459-2465.

92. Sperati CJ, Moliterno AR. Thrombotic microangiopathy: focus on atypical hemolytic uremic syndrome. Hematol Oncol Clin North Am. 2015;29(3):541-559.

93. Cataland SR, Holers VM, Geyer S, Yang S, Wu HM. Biomarkers of terminal complement activation confirm the diagnosis of aHUS and differentiate aHUS from TTP. Blood. 2014;123(24):3733-3738.

94. Timmermans SAMEG, et al. C5b9 formation on endothelial cells reflects complement defects among patients with renal thrombotic microangiopathy and severe hypertension. J Am Soc Nephrol. 2018;29(8):2234-2243.

95. Galbusera M, et al. An ex vivo test of complement activation on endothelium for individualized eculizumab therapy in hemolytic uremic syndrome. Am J Kidney Dis. 2019;74(1):56-72.

96. Chapin J, Shore T, Forsberg P, Desman G, Van Besien K, Laurence J. Hematopoietic transplantassociated thrombotic microangiopathy: case report and review of diagnosis and treatments. Clin Adv Hematol Oncol. 2014;12(9):565-573.

97. Gavriilaki E, et al. Modified Ham test for atypical hemolytic uremic syndrome. Blood. 2015;125(23):3637-3646.

98. Vaught AJ, et al. Direct evidence of complement activation in HELLP syndrome: a link to atypical hemolytic uremic syndrome. Exp Hematol. 2016;44(5):390-398.

99. Vaught AJ, et al. Germline mutations in the alternative pathway of complement predispose to HELLP syndrome. JCI Insight. 2018;3(6):99128.

100.Gavriilaki E, Gkaliagkousi E, Grigoriadis S, Anyfanti P, Douma S, Anagnostopoulos A. Hypertension in hematologic malignancies and hematopoietic cell transplantation: an emerging issue with the introduction of novel treatments. Blood Rev. 2019;35:51-58.

101.Caprioli J, et al. Genetics of HUS: the impact of $\mathrm{MCP}, \mathrm{CFH}$, and IF mutations on clinical presentation, response to treatment, and outcome. Blood. 2006;108(4):1267-1279.

102. Legendre CM, et al. Terminal complement inhibitor eculizumab in atypical hemolytic-uremic syndrome. N Engl J Med. 2013;368(23):2169-2181.

103. Rathbone J, Kaltenthaler E, Richards A, Tappenden P, Bessey A, Cantrell A. A systematic review of eculizumab for atypical haemolytic uraemic syndrome (aHUS). BMJOpen. 2013;3(11):e003573.

104.Walle JV, Delmas Y, Ardissino G, Wang J, Kincaid $\mathrm{JF}$, Haller H. Improved renal recovery in patients with atypical hemolytic uremic syndrome following rapid initiation of eculizumab treatment. J Nephrol. 2017;30(1):127-134.

105. Greenbaum LA, et al. Eculizumab is a safe and effective treatment in pediatric patients with atypical hemolytic uremic syndrome. Kidney Int. 2016;89(3):701-711.

106. Licht C, et al. Efficacy and safety of eculizumab in atypical hemolytic uremic syndrome from 2-year extensions of phase 2 studies. Kidney Int. 2015;87(5):1061-1073.

107. Merrill SA, Brittingham ZD, Yuan X, Moliterno AR, Sperati CJ, Brodsky RA. Eculizumab cessation in atypical hemolytic uremic syndrome. Blood. 2017;130(3):368-372.

108. Ardissino G, et al. Discontinuation of eculizumab maintenance treatment for atypical hemolytic uremic syndrome: a report of 10 cases. Am J Kidney Dis. 2014;64(4):633-637.

109. Macia M, et al. Current evidence on the discontinuation of eculizumab in patients with atypical haemolytic uraemic syndrome. Clin Kidney J. 
2017;10(3):310-319.

110. Hayes W, Tschumi S, Ling SC, Feber J, Kirschfink M, Licht C. Eculizumab hepatotoxicity in pediatric aHUS. Pediatr Nephrol. 2015;30(5):775-781.

111. Nester CM, Smith RJ. Complement inhibition in C3 glomerulopathy. Semin Immunol. 2016;28(3):241-249.

112. Osborne AJ, et al. Statistical validation of rare complement variants provides insights into the molecular basis of atypical hemolytic uremic syndrome and $\mathrm{C} 3$ glomerulopathy. J Immunol. 2018;200(7):2464-2478.

113. Pickering MC, et al. Uncontrolled C3 activation causes membranoproliferative glomerulonephritis in mice deficient in complement factor $\mathrm{H}$. Nat Genet. 2002;31(4):424-428.

114. Regunathan-Shenk R, et al. Kidney transplantation in C3 glomerulopathy: a case series. $\mathrm{Am} J$ Kidney Dis. 2019;73(3):316-323.

115. Garg N, et al. C3 glomerulonephritis secondary to mutations in factors $\mathrm{H}$ and $\mathrm{I}$ r rapid recurrence in deceased donor kidney transplant effectively treated with eculizumab. Nephrol Dial Transplant. 2018;33(12):2260-2265.

116. Gurkan S, Fyfe B, Weiss L, Xiao X, Zhang Y, Smith RJ. Eculizumab and recurrent C3 glomerulonephritis. Pediatr Nephrol. 2013;28(10):1975-1981.

117. Tortajada A, Gutierrez E, Pickering MC, Praga Terente M, Medjeral-Thomas N. The role of complement in IgA nephropathy. Mol Immunol. 2019;114:123-132.

118. Weinstein L. Syndrome of hemolysis, elevated liver enzymes, and low platelet count: a severe consequence of hypertension in pregnancy. $A m J$ Obstet Gynecol.1982;142(2):159-167.

119. Richani K, et al. Normal pregnancy is characterized by systemic activation of the complement system. J Matern Fetal Neonatal Med. 2005;17(4):239-245.

120. Derzsy Z, Prohászka Z, Rigó J, Füst G, Molvarec A. Activation of the complement system in normal pregnancy and preeclampsia. Mol Immunol. 2010;47(7-8):1500-1506.

121. Sarno L, Tufano A, Maruotti GM, Martinelli P, Balletta MM, Russo D. Eculizumab in pregnancy: a narrative overview. J Nephrol. 2019;32(1):17-25.

122. Gavriilaki E, Sakellari I, Anagnostopoulos A, Brodsky RA. Transplant-associated thrombotic microangiopathy: opening Pandora's box. Bone Marrow Transplant. 2017;52(10):1355-1360.

123. Kennedy GA, Bleakley S, Butler J, Mudie K, Kearey N, Durrant S. Posttransplant thrombotic microangiopathy: sensitivity of proposed new diagnostic criteria. Transfusion. 2009;49(9):1884-1889.

124. Jodele S, et al. Abnormalities in the alternative pathway of complement in children with hematopoietic stem cell transplant-associated thrombotic microangiopathy. Blood. 2013;122(12):2003-2007.

125. Gavriilaki E, et al. Linking complement activation, coagulation, and neutrophils in transplant-associated thrombotic microangiopathy. Thromb Haemost. 2019;119(9):1433-1440.

126. Gavriilaki E, et al. Pretransplant genetic susceptibility: Clinical relevance in transplant-associated thrombotic microangiopathy [published online ahead of print March 4, 2020]. Thromb Haemost. https://doi.org/10.1055/s-0040-1702225.
127. Jodele S, et al. Diagnostic and risk criteria for HSCT-associated thrombotic microangiopathy: a study in children and young adults. Blood. 2014;124(4):645-653.

128. Jodele $\mathrm{S}$, et al. Terminal complement blockade after hematopoietic stem cell transplantation is safe without meningococcal vaccination. Biol Blood Marrow Transplant. 2016;22(7):1337-1340.

129.Vasu S, et al. Eculizumab therapy in adults with allogeneic hematopoietic cell transplantassociated thrombotic microangiopathy. Bone Marrow Transplant. 2016;51(9):1241-1244.

130. de Fontbrune FS, et al. Use of eculizumab in patients with allogeneic stem cell transplantassociated thrombotic microangiopathy: a study from the SFGM-TC. Transplantation. 2015;99(9):1953-1959.

131. Bohl SR, et al. Thrombotic microangiopathy after allogeneic stem cell transplantation: a comparison of eculizumab therapy and conventional therapy. Biol Blood Marrow Transplant. 2017;23(12):2172-2177.

132. Jodele S, et al. Complement blockade for TA-TMA: lessons learned from large pediatric cohort treated with eculizumab [published online ahead of print January 13, 2020]. Blood. https:// doi.org/10.1182/blood.2019004218.

133. Goodship THJ, et al. Use of the complement inhibitor Coversin to treat HSCT-associated TMA. Blood Adv. 2017;1(16):1254-1258.

134. Rambaldi A, et al. Improved survival following OMS721 treatment of hematopoieic stem cell transplant-associated thrombotic microangiopathy (HCT-TMA). Paper presented at: 23rd Congress of the European Hematology Association; June 14-17, 2018; Stockholm, Sweden. http:// library.ehaweb.org/eha/2018/stockholm/ 215162/alessandro.rambaldi.improved.survival. following.oms721.treatment.of.html. Updated June 15, 2018. Accessed March 9, 2020.

135. Miyakis S, et al. International consensus statement on an update of the classification criteria for definite antiphospholipid syndrome (APS). J Thromb Haemost. 2006;4(2):295-306.

136. Cervera R, et al. Morbidity and mortality in the antiphospholipid syndrome during a 10 -year period: a multicentre prospective study of 1000 patients. Ann Rheum Dis. 2015;74(6):1011-1018.

137. Cervera R, Espinosa G. Update on the catastrophic antiphospholipid syndrome and the "CAPS Registry." Semin Thromb Hemost. 2012;38(4):333-338.

138. Pierangeli SS, Girardi G, Vega-Ostertag M, Liu X, Espinola RG, Salmon J. Requirement of activation of complement C3 and C5 for antiphospholipid antibody-mediated thrombophilia. Arthritis Rheum. 2005;52(7):2120-2124.

139. Carrera-Marín A, et al. C6 knock-out mice are protected from thrombophilia mediated by antiphospholipid antibodies. Lupus. 2012;21(14):1497-1505.

140. Fischetti F, et al. Thrombus formation induced by antibodies to beta2-glycoprotein I is complement dependent and requires a priming factor. Blood. 2005;106(7):2340-2346.

141. Agostinis C, et al. A non-complement-fixing antibody to $\beta 2$ glycoprotein I as a novel therapy for antiphospholipid syndrome. Blood. 2014;123(22):3478-3487.
142. Girardi G, et al. Complement C5a receptors and neutrophils mediate fetal injury in the antiphospholipid syndrome. JClin Invest. 2003;112(11):1644-1654.

143. Girardi G, Redecha P, Salmon JE. Heparin prevents antiphospholipid antibody-induced fetal loss by inhibiting complement activation. Nat Med. 2004;10(11):1222-1226.

144.Redecha P, et al. Tissue factor: a link between C5a and neutrophil activation in antiphospholipid antibody induced fetal injury. Blood. 2007;110(7):2423-2431.

145. Davis WD, Brey RL. Antiphospholipid antibodies and complement activation in patients with cerebral ischemia. Clin Exp Rheumatol. 1992;10(5):455-460.

146.Breen KA, Seed P, Parmar K, Moore GW, StuartSmith SE, Hunt BJ. Complement activation in patients with isolated antiphospholipid antibodies or primary antiphospholipid syndrome. Thromb Haemost. 2012;107(3):423-429.

147. Devreese KM, Hoylaerts MF. Is there an association between complement activation and antiphospholipid antibody-related thrombosis? Thromb Haemost. 2010;104(6):1279-1281.

148. Chaturvedi S, Brodsky RA, McCrae KR. Complement in the pathophysiology of the antiphospholipid syndrome. Front Immunol. 2019;10:449.

149. Chaturvedi $\mathrm{S}$, et al. Complement activity and complement regulatory gene mutations are associated with thrombosis in APS and CAPS. Blood. 2020;135(4):239-251.

150. Meroni PL, et al. Complement activation in antiphospholipid syndrome and its inhibition to prevent rethrombosis after arterial surgery. Blood. 2016;127(3):365-367.

151. Shapira I, Andrade D, Allen SL, Salmon JE. Brief report: induction of sustained remission in recurrent catastrophic antiphospholipid syndrome via inhibition of terminal complement with eculizumab. Arthritis Rheum. 2012;64(8):2719-2723.

152. Wig S, Chan M, Thachil J, Bruce I, Barnes T. A case of relapsing and refractory catastrophic anti-phospholipid syndrome successfully managed with eculizumab, a complement 5 inhibitor. Rheumatology (Oxford). 2016;55(2):382-384.

153. Zikos TA, Sokolove J, Ahuja N, Berube C. Eculizumab induces sustained remission in a patient with refractory primary catastrophic antiphospholipid syndrome. JClin Rheumatol. 2015;21(6):311-313.

154. Strakhan M, Hurtado-Sbordoni M, Galeas N, Bakirhan K, Alexis K, Elrafei T. 36-year-old female with catastrophic antiphospholipid syndrome treated with eculizumab: a case report and review of literature. Case Rep Hematol. 2014;2014:704371.

155. Lonze BE, et al. Eculizumab prevents recurrent antiphospholipid antibody syndrome and enables successful renal transplantation. Am J Transplant. 2014;14(2):459-465.

156. Gilhus NE, Skeie GO, Romi F, Lazaridis K, Zisimopoulou P, Tzartos S. Myasthenia gravis - autoantibody characteristics and their implications for therapy. Nat Rev Neurol. 2016;12(5):259-268.

157. Engel AG, Arahata K. The membrane attack complex of complement at the endplate in myasthenia gravis. Ann N Y Acad Sci. 1987;505:326-332. 
158. Fazekas A, Komoly S, Bózsik B, Szobor A. Myasthenia gravis: demonstration of membrane attack complex in muscle end-plates. Clin Neuropathol. 1986;5(2):78-83.

159. Basta M, Illa I, Dalakas MC. Increased in vitro uptake of the complement $\mathrm{C} 3 \mathrm{~b}$ in the serum of patients with Guillain-Barré syndrome, myasthenia gravis and dermatomyositis. JNeuroimmunol. 1996;71(1-2):227-229.

160. Romi F, Kristoffersen EK, Aarli JA, Gilhus NE. The role of complement in myasthenia gravis: serological evidence of complement consumption in vivo. J Neuroimmunol. 2005;158(1-2):191-194.

161. Tüzün E, Scott BG, Goluszko E, Higgs S, Christadoss P. Genetic evidence for involvement of classical complement pathway in induction of experimental autoimmune myasthenia gravis. JImmunol. 2003;171(7):3847-3854.

162.Chamberlain-Banoub J, Neal JW, Mizuno M, Harris CL, Morgan BP. Complement membrane attack is required for endplate damage and clinical disease in passive experimental myasthenia gravis in Lewis rats. Clin Exp Immunol. 2006;146(2):278-286.

163. Lin F, Kaminski HJ, Conti-Fine BM, Wang W, Richmonds C, Medof ME. Markedly enhanced susceptibility to experimental autoimmune myasthenia gravis in the absence of decayaccelerating factor protection. J Clin Invest. 2002;110(9):1269-1274.

164. Morgan BP, Chamberlain-Banoub J, Neal JW, Song W, Mizuno M, Harris CL. The membrane attack pathway of complement drives pathology in passively induced experimental autoimmune myasthenia gravis in mice. Clin Exp Immunol.
2006;146(2):294-302.

165. Kusner LL, Halperin JA, Kaminski HJ. Cel surface complement regulators moderate experimental myasthenia gravis pathology. Muscle Nerve. 2013;47(1):33-40.

166. Chamberlain JL, Huda S, Whittam DH, Matiello M, Morgan BP, Jacob A. Role of complement and potential of complement inhibitors in myasthenia gravis and neuromyelitis optica spectrum disorders: a brief review [published online ahead of print September 3, 2019]. J Neurol. https://doi. org/10.1007/s00415-019-09498-4.

167. Howard JF, et al. Safety and efficacy of eculizum$\mathrm{ab}$ in anti-acetylcholine receptor antibodypositive refractory generalised myasthenia gravis (REGAIN): a phase 3, randomised, double-blind, placebo-controlled, multicentre study. Lancet Neurol. 2017;16(12):976-986.

168. Kessler RA, Mealy MA, Levy M. Treatment of neuromyelitis optica spectrum disorder: acute, preventive, and symptomatic. Curr Treat Options Neurol. 2016;18(1):2.

169.Jiao Y, et al. Updated estimate of AQP4-IgG serostatus and disability outcome in neuromyelitis optica. Neurology. 2013;81(14):1197-1204.

170.Waters $P$, et al. Multicentre comparison of a diagnostic assay: aquaporin- 4 antibodies in neuromyelitis optica. J Neurol Neurosurg Psychiatry. 2016;87(9):1005-1015.

171. Hinson SR, et al. Molecular outcomes of neuromyelitis optica (NMO)-IgG binding to aquaporin-4 in astrocytes. Proc Natl Acad Sci U S A. 2012;109(4):1245-1250.

172. Saadoun S, Waters P, Bell BA, Vincent A, Verkman AS, Papadopoulos MC. Intra-cerebral injection of neuromyelitis optica immunoglobulin G and human complement produces neuromyelitis optica lesions in mice. Brain. 2010;133(pt 2):349-361.

173. Duan T, Smith AJ, Verkman AS. Complementdependent bystander injury to neurons in AQP4IgG seropositive neuromyelitis optica. J Neuroinflammation. 2018;15(1):294.

174. Tradtrantip L, Duan T, Yeaman MR, Verkman AS. CD55 upregulation in astrocytes by statins as potential therapy for AQP4-IgG seropositive neuromyelitis optica. J Neuroinflammation. 2019;16(1):57.

175. Pittock SJ, et al. Eculizumab in AQP4-IgG-positive relapsing neuromyelitis optica spectrum disorders: an open-label pilot study. Lancet Neurol. 2013;12(6):554-562.

176. Pittock SJ, et al. Eculizumab in aquaporin-4-positive neuromyelitis optica spectrum disorder. NEngl J Med. 2019;381(7):614-625.

177. Collongues N, Ayme-Dietrich E, Monassier L, de Seze J. Pharmacotherapy for neuromyelitis optica spectrum disorders: current management and future options. Drugs. 2019;79(2):125-142.

178. Yehoshua Z, et al. Systemic complement inhibition with eculizumab for geographic atrophy in agerelated macular degeneration: the COMPLETE study. Ophthalmology. 2014;121(3):693-701.

179. Hajishengallis G, et al. Complement inhibition in pre-clinical models of periodontitis and prospects for clinical application. Semin Immunol. 2016;28(3):285-291.

180. Chen M, Jayne DRW, Zhao MH. Complement in ANCA-associated vasculitis: mechanisms and implications for management. Nat Rev Nephrol. 2017;13(6):359-367. 